\section{SYMPOSIUM ON POISONING}

Paediatric and Accident and Emergency trainees are frequently faced with a child who may have been poisoned by an ingested drug or household product. This month we present a five part symposium on poisoning which we hope will help them decide upon the best course of action. Readers may wish to broadcast the symposium throughout their institution or incorporate it within their own departmental guidelines. We are grateful to the team from Birmingham Children's Hospital who put together the information.

See pages 391-409

\section{SUCCESS WITH nCPAP IN OBSTRUCTIVE SLEEP APNOEA}

For 20 years it has been evident that obstructive sleep apnoea, unresponsive to adenotonsillectomy, is best managed with continuous positive airway pressure. Case series have been reported previously from the US and Australia; this month we report the results obtained in a UK clinic (Great Ormond Street Hospital for Children) managing 66 such children over a 6 year period Treatment was maintained successfully in two-thirds. As well as detailing how to investigate such children and the techniques involved in treatment, the authors provide essential information on how to acclimatise families to the complexities of the procedure and how to ensure maximum compliance by children who might be reluctant or frankly antagonistic to the device.

The thoroughness of the report should enable others to set up similar programmes without having to reinvent wheels. In the UK there may be an added incentive at present. Although examination of removed tonsils for prions has so far proved negative, because of the theoretical passage of vCJD by surgical instruments used on lymphoid tissue, NHS hospitals

www.archdischild.com were advised to use disposable equipment only in carrying out adenotonsillectomy. ${ }^{2}$ Unfortunately, surgeons reported problems with the instruments and at least two deaths may have been associated with this. In consequence many ENT surgeons have stopped operating, pending redesign and bench testing of new instruments. Waiting lists for operations are growing. While this may be a disguised advantage for some children who will spontaneously recover from recurrent infection, it is a misfortune for those in whom operation was indicated by obstructive sleep apnoea. nCPAP can be used as an alternative while awaiting resolution of the impasse.

See page 437

\section{CUTTING EDGE OR CHANCE ASSOCIATION?}

Editors can tell when they receive something innovative when it proves difficult to find informed reviewers to help assess a study's originality and importance. One such study is published this month from Rome. A child suffered multiple injuries in a road traffic accident, including a severe crush syndrome of her left leg. After a failed fasciotomy and in imminent danger of gangrene and a need for amputation, the authors successfully employed the experimental treatment of multiple subcutaneous injections of nerve growth factor (NGF).

Of course, one swallow does not make a summer (even in sunny Italy), but the authors supply a credible argument for the likely efficacy of NGF relating to its ability to stimulate production of vascular endothelial growth factor, which, in turn, promotes angiogenesis. We realise that this case report is unlikely to have an immediate impact for our patients but we publish it as an example of what the future might hold. If NGF lives up to its promise, remember, you heard it here first.

See page 447

\section{DOES BRONCHIOLITIS MAKE YOU WHEEZE?}

In 1995 we published an important paper showing that infants who subsequently suffered bronchiolitis already had a pre-existing abnormality of lung function when prospectively tested at 1 month of age. ${ }^{3}$

The same team now show that the reduction in lung function experienced long term post-bronchiolitis is consistent with the level of premorbid disturbance. They conclude that the mechanism whereby children have abnormal lung function after this viral infection has more to do with their premorbid state than the effect of bronchiolitis per se. The importance of their paper is that it presents results from the only longitudinal study to have included measures of lung function before and after bronchiolitis. The authors conclude that interventions aimed at restoring normal function after bronchiolitis are likely to be futile.

See page 416

\section{SORRY TO HODGE AND PUNTIS}

Many readers will have missed an important paper published in June entitled "Diagnosis, prevention, and management of catheter related bloodstream infection during long term parenteral nutrition" (Arch Dis Child Fetal Neonatal Ed 2002;87:2 1-4). Replying to a rapid response, the authors accuse us of "an arguably perverse editorial decision" (namely lodging the paper in F\&N instead of ADC). We disagree: we weren't perverse, just plain stupid. Or, as we prefer to think, our computer system was. Be thankful we merely edit a scientific journal rather than pilot an airliner.

Anyway, if you are at all interested in infection related to long term parenteral nutrition, please take July's F\&N out of its wrapper, or proceed immediately to www.archdischild.com where all is revealed. Meanwhile, we comfort ourselves with a congratulatory letter from Jerrold Lucey, editor of Pediatrics for as long as we can remember, telling us he found at least seven important papers in that issue of F\&N.

\section{References}

1 Hilton DA. vCJD-predicting the future? Neuropathol Appl Neurobiol 2000;26:405-7.

2 Dyer O. Hospitals to spend $£ 200 m$ to prevent spread of CJD. BM 2001;322:68

3 Young S, O'Keefe PT, Arnott J, et al. Lung function, airway responsiveness and respiratory symptoms before and after bronchiolitis. Arch Dis Child 1995;72:16-24. 